\title{
Anthropogenic climate change and the nature of Earth System science
}

The Anthropocene Review 20I4, Vol. I (I) 70-75

(c) The Author(s) 2014

Reprints and permissions: sagepub.co.uk/journalsPermissions.nav DOI: $10.1|77 / 20530196| 35 \mid 4862$ anr.sagepub.com

(SAGE

\section{Frank Oldfield' and Will Steffen ${ }^{2,3}$}

\begin{abstract}
One of the criticisms made by those sceptical of the majority scientific consensus on climate change and its likely future consequences is that the Earth System science upon which it is based is fundamentally flawed. This contention is challenged here by an outline of the nature of the science needed to make future projections possible. The classic Popperian approach to science, in which potentially refutable hypotheses are defined and tested is not well suited to the challenges posed by an Earth System that is characterised by high degrees of complexity, non-linearity and a lack of definable cause-consequence relationships. A science based on model-data comparisons and interactions is the only effective approach both to increasing our understanding of the Earth System and developing a well substantiated basis for future projections.
\end{abstract}

\section{Keywords}

Anthropocene, climate change sceptics, Earth System science

\section{Introduction}

Anthropogenic climate change - human activities that alter the energy balance at the Earth's surface and destabilise the climate system - is a core framing issue for the Anthropocene, irrespective of the date favoured for its onset. The first instalment of the Fifth IPCC Assessment report of the Intergovernmental Panel on Climate Change (IPCC, 2013) - the Summary for Policy Makers for the Working Group 1 (Physical Science Basis) - has just emerged after much deliberation among hundreds of scientists.

The most recent IPCC report has increased the level of confidence, already high, in the scientific community's basic understanding of the causes and effects of anthropogenic climate change. First, warming of the climate system is unequivocal. Second, we are even more certain that human activities, mainly the emission of greenhouse gases, are the primary cause for the warming observed

IUniversity of Liverpool, UK

${ }^{2}$ The Climate Council of Australia, Australia

${ }^{3}$ The Australian National University, Australia

\section{Corresponding author:}

Frank Oldfield, School of Environmental Sciences, University of Liverpool, Roxby Building, Liverpool L69 3BX, UK.

Email: oldfield.f@gmail.com 
since the mid 20th century. Third, climate change creates serious risks for human wellbeing, often through the exacerbation of extreme weather events. Finally, rapid and deep reductions in greenhouse gas emissions are required to stabilise the climate system this century.

Predictably, the IPCC report has generated renewed, sceptical responses. Indeed, a disinformation campaign had already sprung up prior to the release of the report, based on leaked copies of early drafts of the report. Most of the sceptic attacks can be immediately dismissed for a number of reasons that are not science-based. Some sceptics are funded by special interest groups, often fossil fuel lobby groups that have much to lose if fossil fuel use is significantly reduced. They often use cherry-picked data and flawed logic to cast doubt on the science involved - the so-called 'merchants of doubt' approach that was thoroughly exposed by the work of Oreskes and Conway (2010) and by Mann (2012). Other attacks are clearly based on underlying political motivations, such as equating climate change science to a push for a world government, or other such ultra-rightwing fear campaigns. Yet others are driven by conspiracy theory - that there is a conspiracy throughout the global scientific community to rig the science so that funding is increased by governments intent on promoting ways of reducing carbon emissions. A few of the sceptics, such as Richard Lindzen, express concern about the veracity of mainstream climate change science, and employ more scientifically based approaches to question the science. This type of critique includes both challenges to specific research programmes, climate models and the inferences based on them (e.g. Lindzen and Choi, 2009; 2011, Lindzen et al., 2001) and also blanket assertions that Earth System science itself is fundamentally flawed (Lindzen, 2013).

In keeping with the aim of a highly transdisciplinary journal such as this one, the present paper addresses the sceptics' concern about the scientific method, and examines the ways in which science itself is evolving to deal with something as challenging and complex as the Earth System.

\section{The nature of Earth System science}

The common assertion is that successive IPCC reports and the wide range of research upon which they are based consist of flawed, incomplete or fuzzy science, sometimes derisively referred to as 'junk science' (http://junksciencearchive.com/). The starting point for this science-based attack on the IPCC, and on mainstream climate science more generally, is that the only valid type of science is that which rests on the testing of falsifiable hypotheses. Sceptics of this persuasion claim that, in the case of climate change, this requires a null hypothesis to the effect that 'currently observed changes in global climate indices and the physical environment, as well as current changes in animal and plant characteristics, are the result of natural variability' (Nongovernmental International Panel on Climate Change (NIPCC), 2013). Their claim is that the evidence so far fails to force rejection of this null hypothesis. Notwithstanding that this claim is incorrect (Blois and Hadly, 2009; Diffenbaugh and Field, 2013; Moritz and Agudo, 2013), the underlying scientific philosophy underpinning the claim is essentially the approach to science outlined by Karl Popper, who, in his formulation, requires crucial tests that refute or fail to refute (but never prove) any given hypothesis. This Popperian model of science (Popper, 1963) is the frame of reference within which the sceptics make the more philosophically based component of their critique. All the other supposedly scientific criticisms are underpinned by the claim that this is the only valid type of science and the rest can be regarded as flawed or invalid.

Other sceptics attack the concept of 'consensus' in science, with obvious reference to the commonly made statement that there is a majority consensus among climate scientists regarding the reality of anthropogenic climate change and its likely consequences. The history of environmental science over the last century tells us, however, that no matter how strong the majority consensus is, 
there is no guarantee that a particular interpretation is correct, especially if new evidence becomes available. Up until the 1960s, the visual evidence for Wegener's hypothesis of 'continental drift' (Wegener, 1929/1966) was largely discounted as coincidental. Only when the mechanism of plate tectonics was promulgated did the idea become accepted by geologists (Blackett et al., 1965). For even longer, the proposal by Milankovitch (1941) that orbital variations triggered major changes in Earth's climate, such as the swings between glacial and interglacial conditions, was a minority view. It took the deciphering of the record of climate change in marine deposits (Hays et al., 1976) to confirm that orbital forcing provided the beat to which global climate responded on multimillennial timescales.

The common theme in these past examples of scientific consensus first rejecting and then embracing new understanding of complex phenomena is uncovering underlying mechanisms. In this, the present state of consensus on anthropogenic climate science (understanding the underlying mechanism leading to widespread consensus) in fact represents the same kind of transition as occurred earlier from initial scepticism about the idea that continents moved or that orbital variations caused ice ages, to widespread consensus among scientists as mechanistic underpinnings of the empirical observations came to light.

Fundamental are the conflicting perspectives arising from different concepts of science. What kind of science is possible and appropriate when research questions are necessarily concerned with changes through time in systems of immense complexity, with many feedbacks and non-linear interactions, and no simple cause and effect relationships? This, in fact, is the fundamental nature of Earth System science and the scientific method involved is much more complex than simply formulating hypotheses and designing experiments to test them (see, e.g., Barnosky and Kraatz, 2007).

\section{Looking back to the future}

All the evidence we have regarding environmental change comes from the past, whether of the previous few seconds as changes are logged continuously, or of the more remote past revealed through the study of environmental archives. The latter are especially important as they provide evidence that has accumulated over decadal to millennial timescales, evidence that is vital for understanding those processes that have shaped the present and promise to drive changes in the future on timescales of critical importance to human populations. The research field as a whole has rarely proved amenable to the Popperian approach, though there are a few striking exceptions that live up to the seminal exhortation by the biologist Ed Deevey, to 'coax history to conduct experiments' (Deevey, 1969). These are exemplified by the work carried out to identify the causes of freshwater acidification (Battarbee et al., 1985). By choosing a variety of field-based case studies with or without key characteristics, each of which was a putative cause of acidification, it proved possible to isolate past variables such as land-use change or catchment afforestation and thereby home in on the only remaining hypothesis not rejected by the evidence, namely the dissemination of industrially generated $\mathrm{SO}_{2}$.

This type of study is exceptional and more often, inferences about past environmental changes are interpreted in the context of multiple working hypotheses, each of which stands equally until further evidence accumulates to narrow the range of potential explanations. Indeed, this approach has proven effective in the historical sciences since TC Chamberlain's publication of his seminal paper 'The Method of Multiple Working Hypotheses' (Chamberlain, 1890). The alternative explanations often need to be presented without choosing among them (Dearing et al., 2006). Despite these limitations, interpretations improve as more data accumulate, better techniques become available and more sophisticated paradigms take hold. 


\section{Toward projective science}

What is clear to any researcher in this field is that the combined effects of an only ever imperfectly knowable past and an inconceivably complex environmental system make it, save in rare instances, impossible to apply the type of reasoning that arises from even post hoc experiments where cause and effect can be discriminated and variables considered in isolation. Some 20 years ago Oldfield tried to trace the evolving nature of scientific reasoning in research on past environmental change. This was prompted by the growing conviction that, as the succeeding 20 years have confirmed, the overarching need for a future-oriented research agenda would increasingly dominate funding priorities (Oldfield, 1993).

In that work, Oldfield contrasted both the more traditional and long-standing inductive approach exemplified by classic compilations such as those of Godwin (1956) and Berglund (1991) and the rather more rare but scientifically compelling deductive research exemplified above, with an emerging agenda in which, instead of through rigorously defined hypothesis testing (whether post hoc or through active experiments), validation had to be sought through the ever-increasing convergence between empirical data and models. Since the latter are all that we have for future projection beyond guesswork, expert opinion and extrapolation, data-model comparisons and interactions must be cornerstones of what Oldfield termed 'projective' science. Transient and 'time frame' data are only available for the past but one important purpose of climate or Earth System models is to project the future. The best that can be done therefore is to test the model outputs against empirical data that reflect as wide a range of relevant processes and boundary conditions as possible, as well as to seek to increase understanding of the complex system interactions involved through model simulations.

Models are vital tools in our efforts to understand extremely complex systems such as the Earth System; in fact, that is their primary purpose. Thus, one of the essential features of any model used to project future changes in the global environment must be its ability to capture well those features and changes securely portrayed by the empirical evidence from the past. Future projections are therefore based on data-model comparisons, an interactive relationship subject to progressive refinement as both strands of the relationship gain in knowledge and skill. The uncertainties attached to projections often reflect, in part at least, the combined statistical 'errors' attached to both. It is hard to see how else to proceed. Certainly, this type of projective science falls outside the Popperian framework of straightforward hypothesis testing (Popper, 1963). Moreover, it will always fall short of 'proof' and be subject to varying degrees of uncertainty, but it will, with sufficient skill, be subject to refinement and increasing confidence in its explanatory and projective power. This is precisely what we are seeing in the IPCC assessments, with their increasing confidence in our understanding of past planetary changes; our strengthening ability to tease out the fundamental physical, chemical and biological (and increasingly human) processes in the climate system and combine them in the framework of complex systems; and our skill in building the quantitative models that capture this improved understanding. It is this emerging new model of science - or more precisely, the emerging understanding that science proceeds in an iterative rather than linear fashion - that underpins the whole business of future projection (University of California Museum of Paleontology, 2013).

Finally, alongside the type of 'projective' science outlined above lie future scenarios that include alternative pathways for human populations, their activities and the consequences of those activities. These rest on both quantitative science and plausible assumptions of human activity into the future. Whereas the former can be refined and filtered by the application of criteria based on the skill with which they capture current reality and past variations, the latter are not amenable to such 
rigorous evaluation. They too, though, are vital components of the Earth System and require the engagement of many areas of scholarship beyond those traditionally considered to be within the realm of Earth System science.

In the latest IPCC Summary for Policymakers (2013), these scenarios are portrayed as Representative Concentration Pathways (RCPs) rather than socio-economic scenarios. The only future projection that gives possible cause for complacency is RCP 2.6, which is theoretically possible provided all emission targets are met (van Vuuren et al., 2011). Current national trends, despite past, partial agreements on emission limitation and continuing rhetoric, seem unlikely to come anywhere near to meeting the targets required. In fact, our emissions are currently tracking nearest to RCP 8.5, the highest of the four pathways. The higher emission scenarios are thus much more probable, suggesting that the future does indeed hold challenges that, for much of humanity, will require a mix of mitigation and adaptation that still lies beyond most policy statements at national or international level. Moreover, for the high-end emission scenarios, the rates of change and projected outcomes may lie beyond the adaptive capacity of much of the human population as well as many aspects of Earth System functioning. The bottom line is clear. Denying the relevance and validity of Earth System science is a highly risky, and possibly catastrophic, approach for humanity to take towards its future.

\section{Acknowledgements}

Grateful thanks to Tony Barnosky, John Dearing, John McNeill and Jan Zalasiewicz for their comments on an earlier draft.

\section{Funding}

This research received no specific grant from any funding agency in the public, commercial, or not-for-profit sectors.

\section{References}

Barnosky AD and Kraatz BP (2007) The role of climatic change in the evolution of mammals. Bioscience 57: 523-532.

Battarbee RW, Flower RJ, Stevenson AC et al. (1985) Lake acidification in Galloway: A palaeoecological test of competing hypotheses. Nature 314: 350-352.

Berglund BE (ed.) (1991) The cultural landscape during 6000 years in southern Sweden - The Ystad project. Ecological Bulletins 41: 495 pp.

Blackett PMS, Bullard E and Runcorn SK (eds) (1965) A symposium on continental drift, held in 28 October 1965. Philosophical Transactions of the Royal Society A 258: 323 pp.

Blois JL and Hadly EA (2009) Mammalian response to Cenozoic climatic change. Annual Review of Earth and Planetary Sciences 37: 181-208.

Chamberlain TC (1890/1965) The Method of Multiple Working Hypotheses. Republished in Science 148: 754-759.

Dearing JA, Battarbee RW, Dikau R et al. (2006) Human-environment interactions: Learning from the past. Regional Environmental Change 6: 1-16.

Deevey ES (1969) Coaxing history to conduct experiments. Bioscience 19: 40-43.

Diffenbaugh NS and Field CB (2013) Changes in ecologically critical terrestrial climate conditions. Science 34: $1486-1492$.

Godwin H (1956) History of the British Flora. Cambridge: Cambridge University Press, 383 pp.

Hays JD, Imbrie J and Shackleton NJ (1976) Variations in the Earth's orbit: Pacemaker of the ice ages. Science 194: 1121-1132. 
Intergovernment Panel on Climate Change (IPCC) (2013) Summary for Policy Makers for the Working Group 1 (Physical Science basis). Available at: www.climatechange2013.org/images/uploads/WGIAR5-SPM_ Approved27Sep2013.pdf.

Lindzen RS (2013) Climate Depot exclusive report. Available at: www.climatedepot.com/2013/09/28/mitclimate-scientist-dr-richard-lindzen-rips-un-ipcc-report.

Lindzen RS and Choi Y-S (2009) On the determination of climate feedbacks from ERBE data. Geophysical Research Letters 36: L16705. DOI: 10.1029/2009GL039628.

Lindzen RS and Choi Y-S (2011) On the observational determination of climate sensitivity and its implications. Asia-Pacific Journal of Atmospheric Science 47: 377-390.

Lindzen RS, Chou M-D and Hou AY (2001) Does the Earth have an adaptive infrared iris? Bulletin of the American Meteorological Society 82: 417-432.

Mann ME (2012). The Hockey Stick and the Climate Wars: Dispatches from the Front Lines. New York: Columbia Press, 384 pp.

Milankovitch M (1941) Kanon der Erdbestrahlung und seine Andwendung auf das Eiszeiten-problem. Belgrade: Royal Serbian Academy. [Canon of Insolation and the Ice-Age Problem. Jerusalem: Israel Program for Scientific Translations (1969).]

Moritz C and Agudo R (2013) The future of species under climate change: Resilience or decline? Science 341: 504-508.

Nongovernmental International Panel on Climate Change (NIPCC) (2013) Climate Change Reconsidered II Physical Science: Summary for Policymakers. Chicago, IL: The Heartland Institute, 23 pp.

Oldfield F (1993) Forward to the past: Changing approaches to Quaternary palaeoecology. In: Chambers FM (ed.) Climate Change and Human Impact on the Landscape. London: Chapman and Hall, pp. 13-19.

Oreskes N and Conway EM (2010) Merchants of Doubt: How a Handful of Scientists Obscured the Truth on Issues from Tobacco Smoke to Global Warming. New York: Bloomsbury Press.

Popper K (1963) Conjectures and Refutations: The Growth of Scientific Knowledge. London: Routledge, 582 pp.

University of California Museum of Paleontology (2013) How science works. Available at: http://undsci. berkeley.edu/lessons/pdfs/complex_flow_handout.pdf.

van Vuuren DP, Edmonds JA, Kainuma M et al. (2011) The Representative Concentration Pathways: An overview. Climatic Change 109: 5-31.

Wegener A (1929/1966) The Origin of Continents and Oceans. New York: Courier Dover Publications. 